\section{Dentists in mountain rescue}

D. Watt ${ }^{1}$

Please send any ideas for feature articles for
consideration to:
Rowena Milan,
British Dental Journal,
The Macmillan Building,
4-6 Crinan Street,
London
N19XW
Email: r.milan@ nature.com

Dental practitioners often lead busy lives. It is amazing how diverse their activities can be after the surgery door has closed. This short article describes how our colleagues volunteer to serve the public in one difficult and hazardous environment - the mountainsides of Cumbria.

The English Lake District is a favourite area for walkers and climbers and even the best prepared of these enthusiasts can come to grief. When this happens, a number of volunteer mountain rescue teams (MRTs) are available to respond. Their members are drawn from all walks of life, including dentists.

\section{Life - and death - on the hills}

It is not always, or even usually, possible to have a medical practitioner available for a callout. Many of the rank-and-file mountain rescue team members are therefore 'advanced trained'. Their Casualty Care Certificates (granted by the Mountain Rescue Council) are gained by attending a long series of lectures on human anatomy, physiology, medical issues and trauma. Strict written, oral and practical examinations follow, and the certificates must be revalidated every three years.

Trauma is a common reason for callouts. We often see multiple injuries after a casualty has tumbled down a rocky cliff. MRT members may be faced with a vast range of emergencies, anything from a sprained wrist to a transected spine. Internal injuries, with possible occult bleeding from spleen or liver, and head injuries of all severities are also regularly seen. Regrettably, a fair proportion of callouts result in the evacuation of the dead, either as a result of trauma, hypothermia or pre-existing medical conditions.

'Ladthwaite, Kirkby Stephen, Cumbria, CA17 4JF

Correspondence to: David Watt

Email:grins@btinternet.com

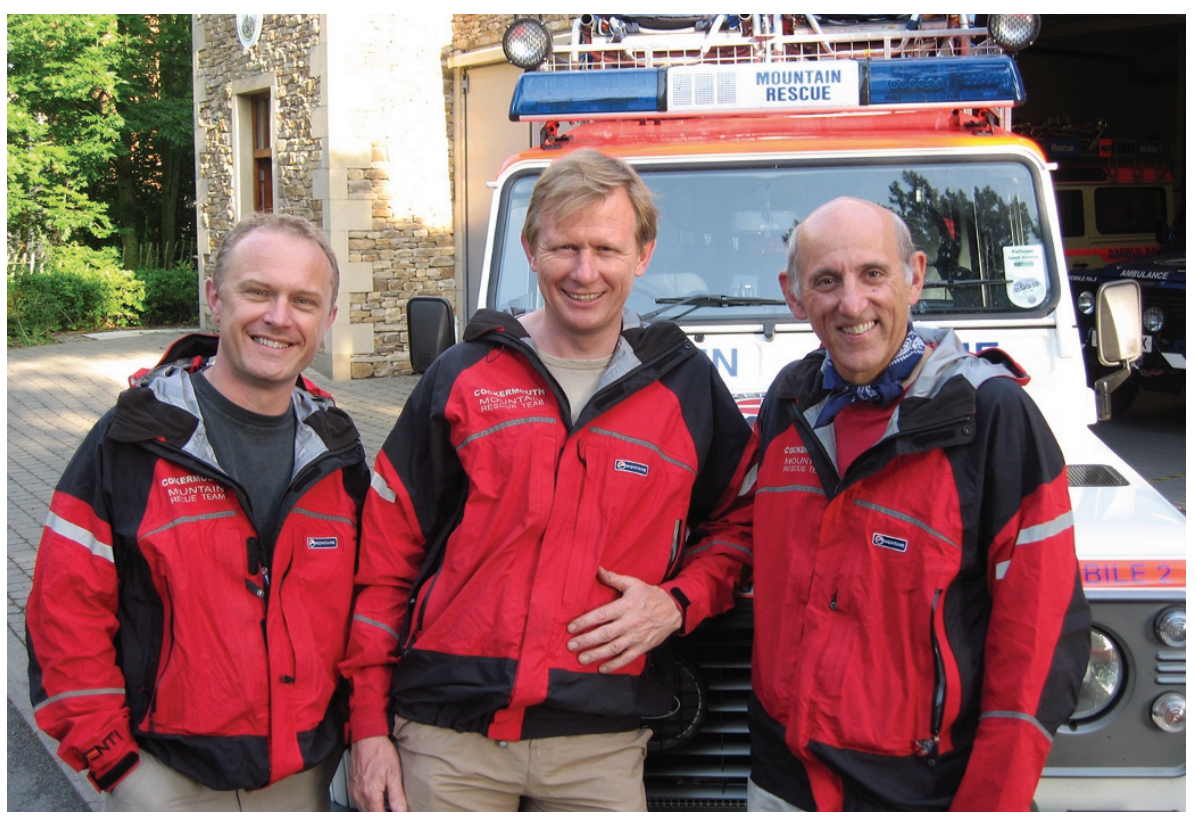

Fig. 1 Left to right: Richard Hellen, Steve Whitehurst and Steve Jones (Cockermouth MRT)

MRTs typically carry a sophisticated emergency medical pack. This includes a drug kit which is very similar to those in every dental surgery: we can treat anaphylaxis, epilepsy, cardiac problems, stroke and diabetes on the hill. We give oxygen and Entonox freely when indicated. Some teams carry intubation equipment and means of securing vascular access; most have defibrillators. The situation on the hill is different from the typical emergency in a dental surgery: it is not uncommon for MRTs to have a casualty under their care for several hours, while a long and laborious stretcher carry-off is completed.

Apart from the mountain work, MRT volunteers have provided assistance during floods and severe winter weather, at rail and air crashes, in searches for missing Alzheimer's disease sufferers or lost children, and in providing first aid cover for mountain marathons.

\section{Dentists' roles}

So where do dentists fit in? The 'ordinary' MRT member is sometimes very reluctant to carry out invasive procedures, mainly because as an individual he or she does not do it very often. For example, it is a challenge to be suddenly faced with giving a morphine injection by torchlight with cold hands on a windy mountainside. There are medico-legal implications, and, should something go wrong, it is a long way to a hospital. Dentists are used to dealing with patients of all sorts, some of them quite distressed, every working 


\section{FEATURE}

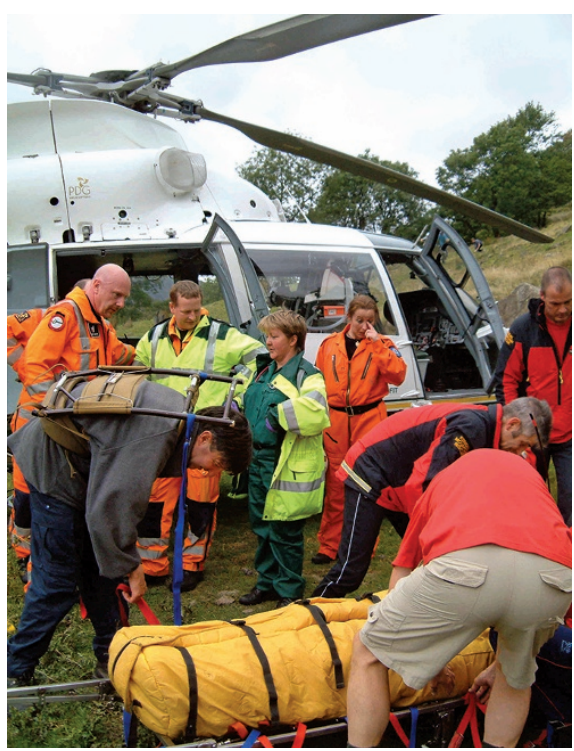

Fig. 2 John Hall, in the red and black jacket, working with the Great North Air Ambulance

day. We constantly monitor them while they are under our care. We have a solid medical and surgical understanding which may give an advantage in diagnosis and treatment using our professional experience. We are very skilled at giving injections - again, perhaps a number of times every day and certainly much more often than a typical GP or paramedic. We monitor airways all the time. And, not least, we are hopefully good at communicating with ambulance or hospital personnel, and good at recording what we have done.

Dental Protection Limited and the Dental Defence Union have proved exceptionally helpful and supportive of dentists in mountain rescue teams. Both organisations have confirmed that they would cover their members for this type of work, provided dentists were operating within the boundaries of their training and competence.

\section{Team members' stories}

Steve Jones, Clinical Director of NHS Cumbria Dental Service, has been a member of Cockermouth MRT for 33 years. Steve specialises in treatment under sedation, and is therefore skilled at securing venous access. He recalls his spell as the team's Medical Officer when the long-serving doctor retired. Steve's baptism came when he was required to administer intravenous morphine to a lady with a badly fractured tibia. He was acutely aware of 20 pairs of eyes, including those of orthodontist Steve Whitehurst and GDP Richard Hellen, both members of the same team (Fig. 1),

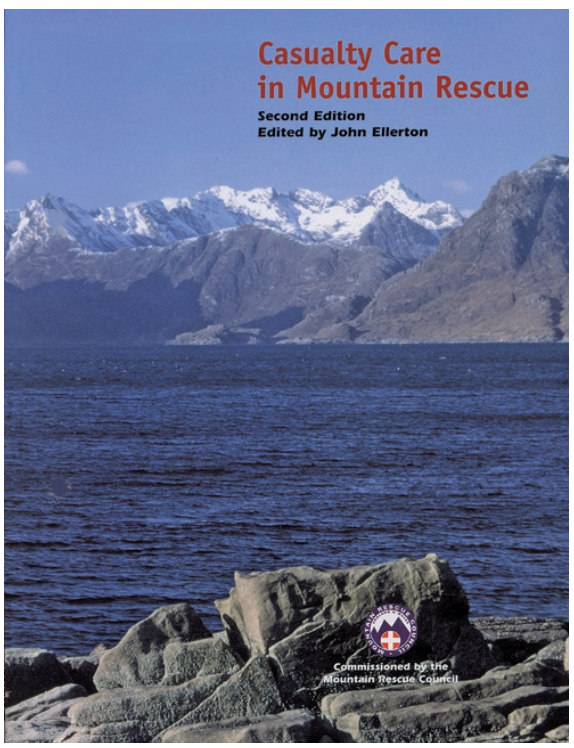

Fig. 3 The textbook Casualty care in mountain rescue

observing the cannulation process, which fortunately was successful.

Having to care for a casualty with a suspected myocardial infarct both on the fellside and during the subsequent RAF Sea King helicopter evacuation was another rewarding and stimulating experience for Steve; again the intravenous route secured safety and control. The trend now is to consider intra-nasal administration for some drugs, especially when hypothermia causes shut-down of peripheral veins.

Iain Wallace, retired GDP and still active in Keswick MRT, was also a dog handler for many years. He recalls treating a

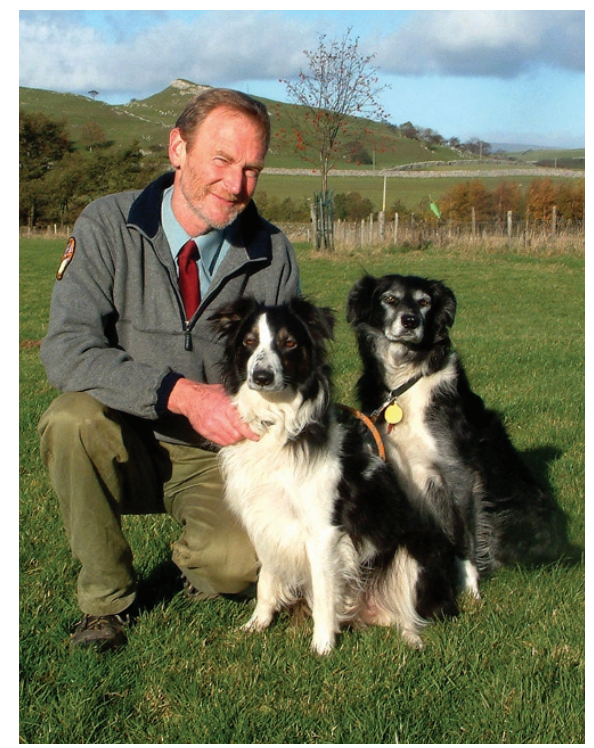

Fig. 4 David Watt with search dogs Flash and Dynamite (Kirkby Stephen MRT)

mountain biker. She had managed to get her handlebar into her mouth, stripping the mucosa off her palate and losing five teeth. It would not have been easy for a lay person to deal with this unpleasant injury.

John Hall (Fig. 2) has been in Kendal MRT for 20 years and has organised a large portion of their medical training. His Team Leader, Andy Dell, tells of an incident when John, on a freezing cold night on the summit of 'Gummers How', was first on the scene. He provided first aid to an unconscious casualty suffering from a drug overdose. The priorities for

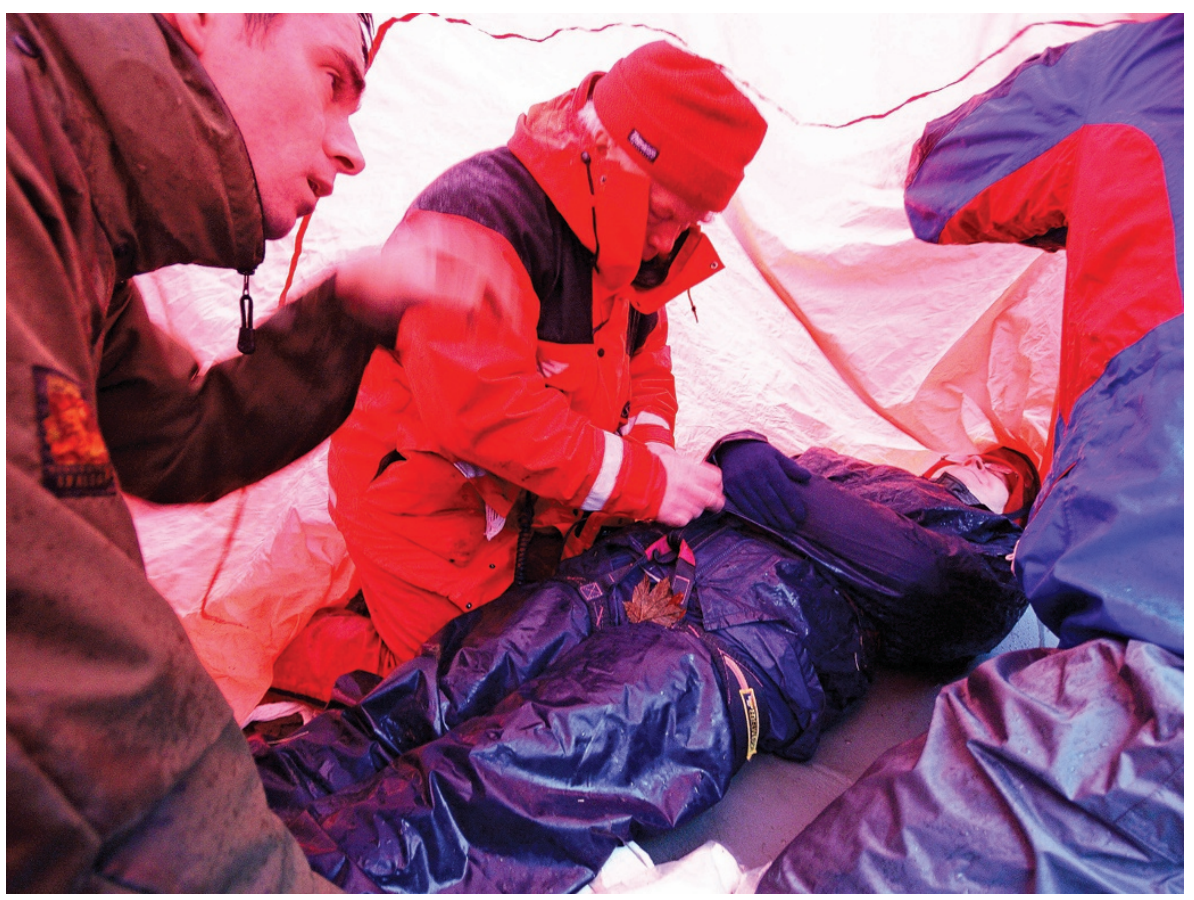

Fig. 5 Team members have to learn to work under less than ideal conditions 
this casualty were to ensure a clear airway and to deliver high flow oxygen with assisted ventilation.

The insertion of an oropharyngeal airway proved impossible due to spasm and so a nasopharyngeal airway was placed. John's request for a helicopter evacuation was declined. The casualty was carried off lying on a stretcher down the steep craggy hillside with constant monitoring, difficult due to the progress of the stretcher. Portable suction, a bag and mask and defibrillator had been taken out of the sacks in preparation for further complications. Only $300 \mathrm{~m}$ from the waiting ambulance the casualty was observed to have stopped breathing and her oxygen saturation plummeted, necessitating further airway management. The casualty recovered fully and is glad to be alive and grateful to the team. John was back in his surgery the next morning and happy to be working in a warm, well lit environment!

David Madley of Leyburn was a member of Kirkby Stephen MRT for many years, became their Medical Officer and also a member of the national Medical Subcommittee. He edited the section on dental and facial injuries in the standard textbook Casualty care in mountain rescue (Fig. 3).

David Watt, a retired GDP, has been a member of Kirkby Stephen MRT for 30 years. He is also a Mountain Rescue Search Dog Handler (Fig. 4). This role involves working alone, usually at night or in poor weather conditions, looking for overdue climbers. A veteran of hundreds of callouts, David recalls one incident where an army cadet in a tent had collapsed, supposedly with exhaustion hypothermia. She was not responding to the usual measures (warmth and glucose). David diagnosed that she was actually suffering from a rare adrenal insufficiency. The casualty made a rapid and complete recovery after David placed crushed steroid tablets under her tongue, as there was no hydrocortisone injection available.

Together with his then associate, Richard Marsden, David produced a pioneering videotape on 'Setting up an IV drip on a mountain' This dealt with the difficulties of finding peripheral veins, with the problems of giving cold fluids and with the practical alternatives to walking for miles with a drip bottle held on high!

And how does this work impact on practice life? MRT volunteers are on call $24 / 7$, but fortunately the peak time for incidents is at weekends, reflecting the increased numbers of people on the hill. Our patients have proved to be very understanding when their Monday morning appointments have been cancelled at short notice. So next time you hear about MRT activities, spare a thought for your colleagues in the team, who have to work in less than ideal conditions (Fig. 5) and are probably quite out of breath!

Mountain Rescue in the Lake District is carried out by volunteers. For more information or to make a donation, please visit the websites www.ldsamra.org.uk and www.sardalakes.org.uk. All support is greatly appreciated.

DOI: 10.1038/sj.bdj.2009.801 